\title{
Molecular Weight Control of Polyphenols by Enzymatic Copolymerization of Phenols
}

\author{
Naruyoshi Mrta, ${ }^{*}, * *$ Shin-ichiro TAWAKI, ${ }^{* *}$ Hiroshi Uyama, ${ }^{* * *}$ and Shiro Kobayashi ${ }^{* * *, ~}{ }^{\dagger}$ \\ ${ }^{*}$ Joint Research Center for Precision Polymerization, Japan Chemical Innovation \\ Institute, NIMC, 1-1 Higashi, Tsukuba, Ibaraki 305-8565, Japan \\ ** Chemical Synthesis Laboratory, Mitsui Chemicals, Inc., 1144 Togo, Mobara, Chiba \\ 297-0017, Japan \\ *** Department of Materials Chemistry, Graduate School of Engineering, Kyoto \\ University, Kyoto 606-8501, Japan
}

(Received December 8, 2000; Accepted January 19, 2001)

\begin{abstract}
KEY WORDS Enzymatic Polymerization / Phenol / Peroxidase / Molecular Weight Control / Oxidative Polymerization /
\end{abstract}

In the last decade, enzymatic syntheses of polyaromatics have been extensively investigated. ${ }^{1-9}$ Oxidative polymerization of various phenol derivatives catalyzed by peroxidase produced a new class of polyphenols showing high thermal stability. ${ }^{10-19}$ The enzymatic process is expected to be an alternative way for preparation of phenolic polymers without use of toxic formaldehyde, which is a monomer for production of conventional phenolic resins (phenol-formaldehyde resins). We have also found that iron- $N, N^{\prime}$-ethylenebis(salicylideneamine) complex (Fe-salen complex), a model complex of peroxidase, efficiently catalyzed an oxidative polymerization of phenol derivatives. ${ }^{20,21}$

We have employed phenol, the simplest and most important phenolic compound in industry, as monomer for the enzymatic oxidative polymerization. The resulting polymer was a powdery material, consisting of a mixture of phenylene and oxyphenylene units (Scheme 1). ${ }^{12,14} \mathrm{In}$ using aqueous 1,4-dioxane as solvent, the polymer was produced in a good yield, however, the solubility of the polyphenol was low; it was partly soluble in $N, N$ dimethylformamide (DMF) and dimethyl sulfoxide (DMSO). Very recently, it was found that the polymer structure and solubility were much influenced by the solvent composition. ${ }^{22,23}$ In the polymerization in a mixture of methanol and buffer, the resulting polyphenol was completely soluble in DMF and DMSO, but insoluble in other organic solvents. Since polymer solubility is crucial for industrial applications, the solubility improvement is strongly desired. This study deals with the molecular weight control of the polyphenols by the enzymatic copolymerization of phenol with substituted phe-



Scheme 1.

${ }^{\dagger}$ To whom correspondence should be addressed. nols, leading to the solubility improvement of the enzymatically obtained polyphenols.

\section{RESULTS AND DISCUSSION}

The copolymerization of phenol with a comonomer was performed by using horseradish peroxidase (HRP) and hydrogen peroxide as catalyst and oxidizing agent, respectively, in a mixture of methanol and phosphate buffer $(\mathrm{pH} 7)$ at room temperature under air. Hydrogen peroxide $(30 \%)$ was added dropwise to the reaction mixture for $3 \mathrm{~h}$. By the addition of hydrogen peroxide, the reaction mixture turned dark-brown, afterwards the powdery precipitates were formed. After $1 \mathrm{~h}$ of the addition of hydrogen peroxide, the polymer was isolated by filtration.

First, we examined the copolymerization with mono-, di-, and tri-substituted phenols: 4-ethylphenol, six dimethylphenols, and 2,4,6-trimethylphenol. In all cases, the comonomer was quantitatively consumed. Except the copolymerization with 2,4,6-trimethylphenol, more than $90 \%$ conversion of phenol was found. Copolymerization results are summarized in Table I. The copolymerization with 2,4-dimethylphenol produced the polyphenol with lower molecular weight than that by the homopolymerization of phenol under the similar reaction conditions (entries 1 and 4). The decrease of the molecular weight was observed in using 2,4,6-trimethylphenol (entry 9), however, the polymer yield also decreased. The low yield was due to the low conversion of phenol (67\%). In the copolymerization with other substituted phenols, the molecular weight slightly decreased or did not change. From these data, 2,4-dimethylphenol was found to be the most suitable as comonomer to produce the polyphenol with lower molecular weight.

Liquid chromatography-mass (LC-MS) and matrixassisted laser desorption/ionization-time of flight mass (MALDI-TOF MS) spectroscopic analysis of the copolymer from phenol and 2,4-dimethylphenol showed the formation of the polymeric product consisting of both monomers; peaks due to the copolymers were observed in MS spectra. The copolymer was readily soluble in 
Table I. HRP-Catalyzed Oxidative Copolymerization of Phenol and Substituted Phenols ${ }^{\mathrm{a}}$

\begin{tabular}{clccc}
\hline Entry & \multicolumn{1}{c}{ Comonomer } & Yield $/ \%$ & $M_{\mathrm{n}}{ }^{\mathrm{b}}$ & $M_{\mathrm{w}} / M_{\mathrm{n}}{ }^{\mathrm{b}}$ \\
\hline 1 & - & 85 & 2200 & 3.0 \\
2 & 4-Ethylphenol & 88 & 1900 & 3.4 \\
3 & 2,3-Dimethylphenol & 88 & 2200 & 3.5 \\
4 & 2,4-Dimethylphenol & 94 & 1100 & 5.2 \\
5 & 2,5-Dimethylphenol & 85 & 2100 & 3.3 \\
6 & 2,6-Dimethylphenol & 79 & 1900 & 3.5 \\
7 & 3,4-Dimethylphenol & 91 & 1700 & 3.4 \\
8 & 3,5-Dimethylphenol & 91 & 2200 & 3.0 \\
9 & 2,4,6-Trimethylphenol & 65 & 1300 & 3.1 \\
\hline
\end{tabular}

${ }^{a}$ Copolymerization of monomers $(10.6 \mathrm{mmol}, 10 \mathrm{~mol} \%$ of comonomer) using HRP catalyst in an equivolume mixture of methanol and $\mathrm{pH} 7$ phosphate buffer $(20 \mathrm{~mL})$ at room temperature under air. ${ }^{\mathrm{b}}$ Determined by SEC using DMF as eluent with polystyrene standards.

Table II. HRP-Catalyzed Oxidative Copolymerization of Phenol and 2,4-Disubstituted Phenols ${ }^{\mathrm{a}}$

\begin{tabular}{clccc}
\hline Entry & \multicolumn{1}{c}{ Comonomer $^{\mathrm{b}}$} & Yield $/ \%$ & $M_{\mathrm{n}}^{\mathrm{c}}$ & $M_{\mathrm{w}} / M_{\mathrm{n}}{ }^{\mathrm{c}}$ \\
\hline 1 & - & 85 & 2200 & 3.0 \\
2 & 2,4-Dimethylphenol (5) & 84 & 1800 & 3.6 \\
3 & 2,4-Dimethylphenol (10) & 94 & 1100 & 5.2 \\
4 & 2,4-Dimethylphenol (20) & 82 & 900 & \\
5 & 2,4-Dimethylphenol (20) & 92 & 760 & \\
6 & 2,4-Dimethylphenol (30) & 88 & 370 & \\
7 & 2,4-Dimethylphenol (40) & 81 & 340 & \\
8 & 2,4-Dimethylphenol (50) & 92 & 190 & \\
9 & 2,4-Dimethylphenol (100) & 85 & 200 & \\
10 & 2,4-Di-tert-butylphenol (10) & 85 & 1600 & 3.9 \\
11 & 2,4-Di-tert-butylphenol (20) & 96 & 1100 & 3.9 \\
\hline
\end{tabular}

${ }^{a}$ Copolymerization of monomers $(10.6 \mathrm{mmol})$ using HRP catalyst in an equivolume mixture of methanol and $\mathrm{pH} 7$ phosphate buffer $(20 \mathrm{~mL})$ at room temperature under air. ${ }^{\mathrm{b}}$ In parentheses: comonomer feed ratio for monomers (mol\%). ${ }^{\mathrm{c}}$ Determined by SEC using DMF as eluent with polystyrene standards. ${ }^{\mathrm{d}}$ Comonomer was added dropwise.

acetone, ethyl acetate, pyridine, and 1,3-dimethyl-2imidazolidinone as well as DMF and DMSO, supporting the copolymer formation from phenol and 2,4dimethylphenol. ${ }^{1} \mathrm{H}$ NMR and IR analyses showed that the polymer structure was of a mixture of phenylene and oxyphenylene units. ${ }^{14}$

Table II shows the copolymerization results using 2,4disubstituted phenols as comonomer. As the feed ratio of 2,4-dimethylphenol increased, the molecular weight decreased (entries 2-4 and 6-8), indicating the strong dependence of the molecular weight on the feed ratio of 2,4-dimethylphenol. In most cases, the formation of the copolymer with broad molecular weight distribution was observed. LC-MS analysis showed that the dimer was mainly obtained in the homopolymerization of 2,4dimethylphenol. This may be related to the formation of the low molecular weight polyphenol in the copolymerization with 2,4-dimethylphenol. In using 2,4-di-tertbutylphenol as comonomer, the decrease of the molecular weight was also observed (entries 10 and 11).

The copolymerization of phenol with 2,4dimethylphenol (feed ratio of $80: 20 \mathrm{~mol} \%$ ) was monitored by using size exclusion chromatography (SEC) (Figure 1). At the initial stage of the copolymerization, the product of the low molecular weight was formed. A similar SEC trace was observed in the homopolymeriza-

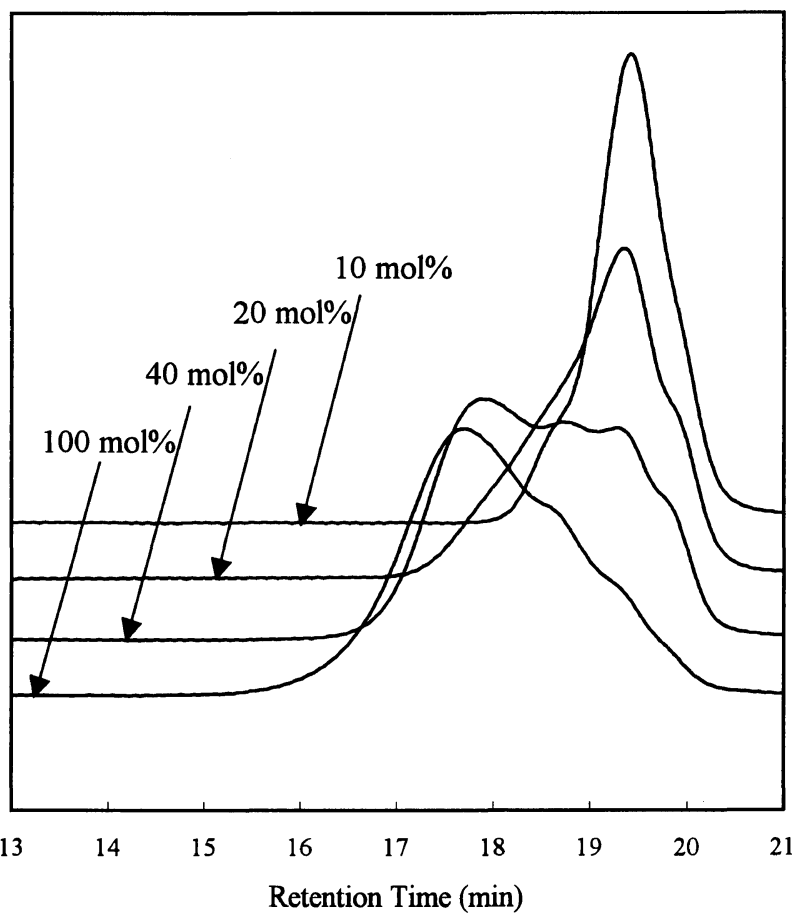

Figure 1. SEC traces of the product obtained by the copolymerization of phenol and 2,4-dimethylphenol ( $80: 20 \mathrm{~mol} \%)$ with different amount of hydrogen peroxide.

tion of 2,4-dimethylphenol, suggesting that the product is the oligomer mainly derived from 2,4-dimethylphenol. This may be because the oxidative reactivity of 2,4dimethylphenol is larger than that of phenol, and hence, 2,4-dimethylphenol was mainly reacted at the initial reaction stage. As a function of the added amount of hydrogen peroxide, the molecular weight increased and the peak intensity of the oligomer became smaller. The final product still contained a small amount of oligomers, resulting in the wide molecular weight distribution.

In order to inhibit the homopolymerization of 2,4dimethylphenol at the initial stage, it was added dropwise for $1.5 \mathrm{~h}$ (entry 5). The molecular weight distribution became narrower and the polymer yield improved in comparison with the copolymerization in the all loading of the monomers (entry 4).

\section{CONCLUSIONS}

The peroxidase-catalyzed copolymerization of phenol with 2,4-disubstituted phenols produced the polyphenols with low molecular weight, which were readily soluble in polar organic solvents. The molecular weight could be controlled by changing the feed ratio of the comonomer. The resulting polyphenols showing high solubility are highly expected to possess potential applications in industrial fields.

\section{EXPERIMENTAL}

HRP was obtained from Toyobo Co. and used without further purification. Other reagents and solvents were commercially available and were used as received.

A typical run was as follows (entry 4 in Table II). Phenol (0.80 g, $8.6 \mathrm{mmol}), 2,4$-dimethylphenol $(0.26 \mathrm{~g}, 2.1$ 
$\mathrm{mmol}$ ) and HRP (24 mg, 240 unit) in an equivolume mixture of methanol and $0.05 \mathrm{M}$ phosphate buffer ( $\mathrm{pH} 7)(20$ $\mathrm{mL}$ ) were placed in a $50 \mathrm{~mL}$ of flask. To the mixture, 1.5 $\mathrm{mL}$ of $30 \%$ hydrogen peroxide $(14.7 \mathrm{mmol})$ was added dropwise for $3 \mathrm{~h}$. The mixture was stirred at room temperature under air. After $1 \mathrm{~h}$, the precipitated materials were collected by filtration and washed with water, followed by drying in vacuo to give $0.88 \mathrm{~g}$ of the polymer (yield $82 \%$ ). ${ }^{1} \mathrm{H}$ NMR (DMSO- $d_{6}$ ): $\delta 1.9-2.4\left(\mathrm{br}, \mathrm{CH}_{3}\right.$ ), 6.2-7.7 (br, Ar); IR (KBr) $3400(v \mathrm{O}-\mathrm{H}), 1588,1489$ ( $v$ $\mathrm{C}=\mathrm{C}$ of $\mathrm{Ar}), 1208(v \mathrm{C}(\mathrm{Ar})-\mathrm{O}-\mathrm{C}(\mathrm{Ar})$ and $\mathrm{C}(\mathrm{Ar})-\mathrm{OH})$, $1102 \mathrm{~cm}^{-1}$ ( $\left.v \mathrm{C}(\mathrm{Ar})-\mathrm{O}-\mathrm{C}(\mathrm{Ar})\right)$.

For SEC and HPLC measurement, a Tosoh SC8020 apparatus was used. SEC analysis was carried out by using a refractive index (RI) detector at $60^{\circ} \mathrm{C}$ under the following conditions: two TSKgel $\alpha-\mathrm{M}$ columns and DMF containing $0.09 \mathrm{M} \mathrm{LiCl}$ eluent at a flow rate of 1.0 $\mathrm{mL} \min ^{-1}$. The calibration curves were obtained using polystyrene standards. HPLC analysis was performed using a UV monitor $(278 \mathrm{~nm})$ at $40^{\circ} \mathrm{C}$ under the following conditions: two YMC-Pack ODS AM-312 columns and methanol/17 $\mathrm{mM}$ phosphoric acid eluent at a flow rate of $1.8 \mathrm{~mL} \mathrm{~min}^{-1}$. LC-MS measurement was carried out on a Waters 2690 chromatography equipped with a Waters 996 photodiode array detector $(200-400 \mathrm{~nm})$ and a micromass ZMD spectrometer under the following conditions: two YMC-Pack ODS AM-312 columns and methanol/water eluent. The mass spectrum was recorded by scanning in the mass range from $\mathrm{m} / \mathrm{z} 100$ to 2000 with an electrospray ionization interface in the negative mode at a cone voltage of $60 \mathrm{~V}$. MALDI-TOF MS measurement was carried out using a JEOL JMSElite mass spectrometer. Molecular weights were recorded using dithranol as matrix in a linear mode. Mass spectra were calibrated with substance $\mathrm{P}$ before measurement. ${ }^{1} \mathrm{H}$ NMR spectra were recorded on a Jeol JNMLA 600 spectrometer. FT-IR measurements were carried out with a Perkin-Elmer Paragon 1000 spectrometer.

Acknowledgments. This work was supported by NEDO for the project on Technology for Novel HighFunctional Materials in Industrial Science and Technology Frontier Program, AIST.

\section{REFERENCES}

1. S. Kobayashi, S. Shoda, and H. Uyama, Adv. Polym. Sci., 121, 1 (1995).

2. S. Kobayashi, S. Shoda, and H. Uyama, "The Polymeric Materials Encyclopedia”, J. C. Salamone, Ed., CRC Press, Boca Raton, FL, 1996, pp 2102-2107.

3. M. Ayyagari, J. A. Akkara, and D. L. Kaplan, Acta Polymerica, 47, 193 (1996).

4. S. Kobayashi, S. Shoda, and H. Uyama, "Catalysis in Precision Polymerization”, S. Kobayashi Ed., John Wiley \& Sons, Inc., Chichester, U. K., 1997, chapt. 8.

5. R. A. Gross, D. L. Kaplan, and G. Swift, Ed., "ACS Symp. Ser.," 1998, vol. 684 .

6. H. Joo, Y. J. Yoo, and J. S. Dordick, Korean. J. Chem. Eng., 15, 362 (1998).

7. S. Kobayashi, J. Polym. Sci., Part A: Polym. Chem., 37, 3041 (1999).

8. H. Uyama and S. Kobayashi, CHEMTECH, 29(10), 22 (1999).

9. J. A. Akkara, M. S. R. Ayyagari, and F. F. Bruno, Trends Biotechnol., 17, 67 (1999).

10. J. S. Dordick, M. A. Marletta, and A. M. Klibanov, Biotechnol. Bioeng., 30, 31 (1987).

11. J. A. Akkara, K. J. Senecal, and D. L. Kaplan, J. Polym. Sci., Polym. Chem. Ed., 29, 1561 (1991).

12. H. Uyama, H. Kurioka, I. Kaneko, and S. Kobayashi, Chem. Lett., 423 (1994).

13. P. Wang, B. D. Martin, S. Parida, D. G. Rethwisch, and J. S. Dordick, J. Am. Chem. Soc., 117, 12885 (1995).

14. H. Uyama, H. Kurioka, J. Sugihara, and S. Kobayashi, Bull. Chem. Soc. Jpn., 69, 189 (1996).

15. S. Kobayashi, H. Kurioka, and H. Uyama, Macromol. Rapid Commun., 17, 503 (1996).

16. R. S. Premachandran, S. Banerjee, X.-K. Wu, V. T. John, G. L. McPherson, J. Akkara, M. Ayyagari, and D. Kaplan, Macromolecules, $\mathbf{2 9}, 6452$ (1996).

17. H. Uyama, C. Lohavisavapanich, R. Ikeda, and S. Kobayashi, Macromolecules, 31, 554 (1998).

18. P. Wang and J. S. Dordick, Macromolecules, 31, 941 (1998).

19. H. Tonami, H. Uyama, S. Kobayashi, T. Fujita, Y. Taguchi, and K. Osada, Biomacromolecules, 1, 149 (2000).

20. H. Tonami, H. Uyama, S. Kobayashi, H. Higashimura, and T. Oguchi, J. Macromol. Sci., Pure Appl. Chem., A36, 719 (1999).

21. H. Tonami, H. Uyama, T. Oguchi, H. Higashimura, and S. Kobayashi, Polym. Bull., 42, 125 (1999).

22. T. Oguchi, S. Tawaki, H. Uyama, and S. Kobayashi, Macromol. Rapid Commun., 20, 401 (1999).

23. T. Oguchi, S. Tawaki, H. Uyama, and S. Kobayashi, Bull. Chem. Soc. Jpn., 73, 1389 (2000). 